
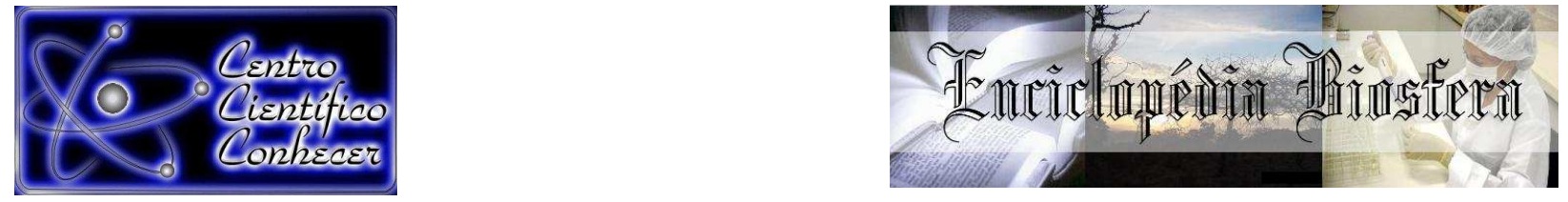

\title{
ANÁLISE BIBLIOMÉTRICA DAS RELAÇÕES ÉTNICO RACIAIS NOS ESTUDOS ORGANIZACIONAIS BRASILEIROS
}

\author{
Maryele Lázara Rezende ${ }^{1}$, Vagner Rosalem ${ }^{2}$.
}

1-Mestranda do Programa de Pós-Graduação em Gestão Organizacional, Universidade Federal de Goiás - Regional Catalão. Catalão - GO, Brasil.(adm.maryele@gmail.com). 2-Docente no Programa de Pós-Graduação em Gestão Organizacional, Universidade Federal de Goiás - Regional Catalão. Catalão - GO, Brasil

Recebido em: 03/10/2016 - Aprovado em: 21/11/2016 - Publicado em: 05/12/2016 DOI: 10.18677/EnciBio_2016B_182

\begin{abstract}
RESUMO
O presente estudo apresenta um levantamento em alguns dos principais periódicos nacionais de administração, afim de categorizar assuntos pertinentes à marginalização dos negros e pardos nos ambientes organizacionais público e privado. Para este estudo foi realizado um recorte dos principais periódicos brasileiros de administração do período de 2002 a 2014. Foi possível verificar que os estudos sobre as relações raciais contam com um pequeno número de publicações e que estão agrupadas somente nas áreas de marketing, estudos organizacionais e administração pública, sugerindo que as pesquisas nessa área devem ser aprofundadas.
\end{abstract}

PALAVRAS-CHAVE: Cotas, Etnias, Organizações.

\section{ANALYSIS BIBLIOMETRIC OF RELATIONS ETHNIC RACIAL IN BRAZILIAN ORGANIZATIONALSTUDIES}

\begin{abstract}
This study presents a survey of some of the major national administration journals in order to, categorize matters pertaining to the marginalization of blacks and mulattos in organizational public and private environments. For this study was made a cut of the main period of 2002 the administration of Brazilian journals to 2014. It was possible to verify that the studies on race relations have a small number of publications and are grouped only in the areas of marketing, organizational studiesand public administration, suggesting that research in this area should go more in depth.
\end{abstract}

KEYWORDS: Ethnic groups, Organizations, Quotas.

\section{INTRODUÇÃO}

O debate sobre as relações étnico raciais tem apresentado grande impacto no ambiente público nas últimas décadas, mas os estudos organizacionais ainda detêm de certo ceticismo em aprofundar no tema. O tema de diversidade tratado nos estudos organizacionais ocupa-se quase que totalmente das relações entre gêneros. Porém, as relações étnicas raciais não devem ser desconsideradas nos estudos organizacionais, uma vez que, referem-se diretamente aos processos seletivos das 
organizações públicas brasileiras e as empresas privadas ao abordarem processos de comunicação, marketing e cultura organizacional (ROSA, 2014).

As cotas raciais nas universidades públicas brasileiras existentes a mais de dez anos. Foi alvo de argumentação e debates entre jornalistas e pesquisadores causando grande repercussão nacional, uma vez que dualizam o senso de justiça dos brasileiros, formando grupos favoráveis as cotas argumentando uma compensação histórica e uma forma paliativa de promover a igualdade entre os brasileiros e por um segundo grupo formado por pessoas que alegam o princípio da isonomia (MELLO et al., 2006).

Para aquecer novamente o polêmico tema, no dia 09 de junho de 2014, a presidente do Brasil sancionou a lei que garante $20 \%$ das vagas aos negros e pardos em concursos públicos federais (BRASIL, 2014). Segundo o site da Presidência da Republica, Dilma considerou o ato uma vitória contra o racismo e oportunidade de demonstrar orgulho pela diversidade brasileira (DILMA, 2016). Tal fato repleto de discussões e ideias controversas realimentam um novo debate sobre as relações étnico raciais nas organizações e justifica tal motivação para escrever este artigo.

Este ensaio teórico teve por objetivo realizar um levantamento nos principais periódicos nacionais de administração, afim de categorizar assuntos pertinentes à marginalização dos negros e pardos no ambiente organizacional, bem como, as cotas ofertadas a afrodescendentes. Espera-se com esse trabalho identificar qual é a relevância das relações raciais nos estudos organizacionais brasileiros.

\section{MATERIAL E MÉTODOS}

O objeto de estudo dessa pesquisa foram as relações raciais existentes no ambiente organizacional brasileiro. Buscou-se caracterizar as diferenças de problemas e ideologias existentes nas organizações públicas e privadas, observando as percepções de pesquisadores brasileiros e os processos que levaram a formação de concepções que assemelham a raça a condições sociais estereotipadas.

Esse trabalho consistiu em uma revisão bibliográfica de caráter qualitativa, opôs um levantamento, catalogação e revisão de trabalhos publicados em eventos e periódicos de administração brasileira. Os dados foram coletados nos periódicos: RAC, BAR, TAC, RAC- Eletrônica, RAP, O \& $S$ e Pretexto. E em anais de eventos como: ENANPAD, ENEO, Simpósio, ENADI, 3es, EMA, EnAPG, ENGPR e ENEPQ, no período crítico de 2002 a 2014. As palavras pesquisadas foram: racial, raciais, negros e afrodescendentes. A busca resultou em 17 artigos encontrados sendo que 13 foram considerados relevantes para a pesquisa. Os outros quatro artigos foram excluídos por que não atenderam ao contexto organizacional, retratando fatores como as expressões carnavalescas e as políticas de cotas empregadas a outras minorias.

A estruturação dos dados foi realizada em um quadro que sintetiza o título do artigo, autores, periódicos, ano de publicação, objetivo, método, resultados, discussões, classificação, tipo de pesquisa, desenho da investigação, palavras chave, área temática, quantidade de referencia.

\section{RESULTADOS E DISCUSSÕES}

No período de análise foram publicados 17 artigos sobre o tema sendo 47\% dos trabalhos publicados em revistas e 53\% em eventos. Dos 13 artigos considerados para a coleta de dados foram $67 \%$ de revisão bibliográfica, $11 \%$ de 
entrevistas, $5 \%$ questionários e $17 \%$ de observações. A classificação entre teórico e empírico corresponderam respectivamente a $36 \%$ e $50 \%$, havendo $14 \%$ dos trabalhos que foram considerados teóricos e empíricos. Quanto ao tipo de pesquisas estas foram consideradas em quantitativas e qualitativas correspondentes a $29 \%$ e $64 \%$ sendo $7 \%$ das pesquisas consideradas quanti-qualitativas. As áreas temáticas distribuíram-se em: marketing $43 \%$, estudos organizacionais $28,5 \%$ e administração pública $28,5 \%$.

QUADRO 1: Relação dos artigos encontrados que abordam as relações raciais no período de 2002 a 2014

\begin{tabular}{|c|c|}
\hline Artigo & Autor/ano \\
\hline $\begin{array}{l}\text { Relações raciais e estudos organizacionais no } \\
\text { Brasil }\end{array}$ & ROSA, (2014). \\
\hline $\begin{array}{l}\text { Interpretaçőes sobre os retratos dos afro- } \\
\text { descendentes na mídia de massa }\end{array}$ & $\begin{array}{l}\text { ACEVEDO; NOHARA, } \\
(2008) \text {. }\end{array}$ \\
\hline $\begin{array}{l}\text { A efetividade dos programas sociais de } \\
\text { acesso à educação superior: } 0 \text { caso } \\
\text { PROUNI }\end{array}$ & $\begin{array}{l}\text { SARAIVA; NUNES, } \\
(2011) \text {. }\end{array}$ \\
\hline $\begin{array}{l}\text { Uma análise das representações } \\
\text { afrodescedentes nas propragandas de jornais } \\
\text { paulistas }\end{array}$ & FARIA et al., (2014). \\
\hline $\begin{array}{l}\text { Uma análise dos a frodescendentes nas } \\
\text { propagandas de jornais paulistas }\end{array}$ & FARIA et al., (2013). \\
\hline $\begin{array}{l}\text { Relações raciais e estudos organizacionais no } \\
\text { Brasil: dimensões esquecidas de um debate } \\
\text { que (ainda) não foi feito }\end{array}$ & ROSA, (2012). \\
\hline $\begin{array}{l}\text { Gestão da diversidade: o desafio dos } \\
\text { negros nas organizações brasileiras }\end{array}$ & OLIVEIRA, (2007). \\
\hline $\begin{array}{l}\text { Um estudo longitudinal das representações } \\
\text { dos afrodescendentes na mídia impressa } \\
\text { brasileira }\end{array}$ & SANTANA et al., (2012). \\
\hline $\begin{array}{l}\text { A adoção da política de cotas nas } \\
\text { universidades públicas brasileiras e sua } \\
\text { repercussão no ensino superior do país }\end{array}$ & MELLO et al., (2006). \\
\hline $\begin{array}{l}\text { A política de cotas nas universidades } \\
\text { brasileiras: como ela chegou à agenda de } \\
\text { políticas públicas? }\end{array}$ & IIZUKA, (2006). \\
\hline $\begin{array}{l}\text { A política pública de cotas na UERJ: } \\
\text { desempenho e inclusão }\end{array}$ & $\begin{array}{l}\text { BEZERRA; GURGEL, } \\
\text { (2012). }\end{array}$ \\
\hline $\begin{array}{l}\text { As ações afirmativas para afrodescendentes } \\
\text { articuladas a partir de parcerias intersetoriais: } \\
\text { uma análise argumentativa do caso geração XXI }\end{array}$ & LORENZO, (2012). \\
\hline $\begin{array}{l}\text { Racismo e anti-racismo: preconceitos, } \\
\text { discriminação e os jovens estudantes nas } \\
\text { escolas cariocas. }\end{array}$ & MAGGIE, (2006). \\
\hline
\end{tabular}

Nos períodos de 2002 a 2005, apesar de ter sido realizada a pesquisa, não foram encontrados registros sobre o tema. $\mathrm{Na}$ análise cronológica dos dados percebeu-se que o tema passou a ter um pouco mais de influência a partir de ENCICLOPÉDIA BIOSFERA, Centro Científico Conhecer - Goiânia, v.13 n.24; p. 1780 
2012, tal fato pode estar relacionado ao momento histórico das cotas raciais no Brasil. Neste mesmo período ocorreu à promulgação da lei 12.711 que reserva vagas nas universidades federais a negros, pardos e indígenas (BRASIL, 2012).

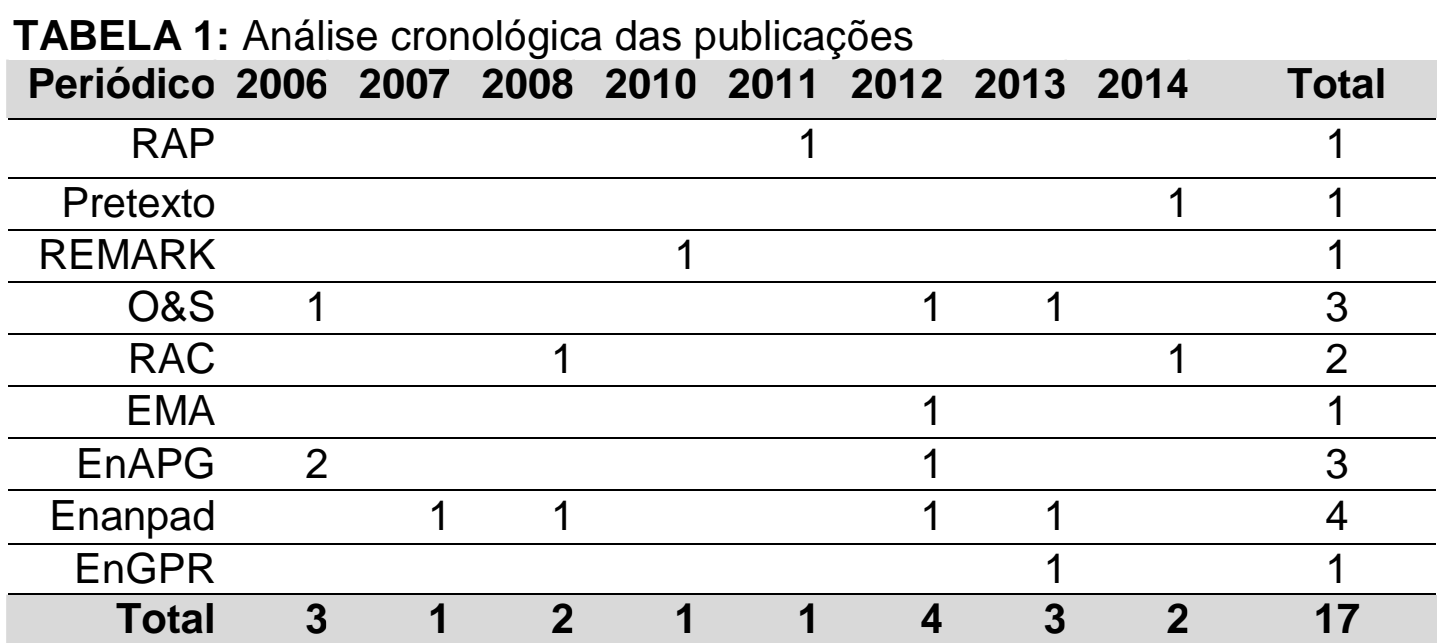

Fonte: elaborado pelos autores, (2016).

O interesse na amostra justifica-se, também, pela existência de um debate nacional sobre as relações raciais que influenciam diretamente as políticas públicas brasileiras e que levou a uma nova política de cotas em concursos públicos federais (BRASIL, 2014).

Quanto a análise dos autores percebeu-se que ROSA (2012; 2014), FARIA et al. $(2013 ; 2014)$ detém mais de uma publicação em diferentes eventos e periódicos sobre o tema, mas tal fato pode não consagrá-los como grandes pesquisadores da área, uma vez que seus trabalhos relatam o mesmo tema e ideias percebendo, em alguns casos, indícios de auto-plágio, situação esta que deve ser analisada a parte e em outro estudo pelos editores dos respectivos periódicos.

Dentre as palavras-chave mais repetidas apresentaram-se: afrodescentente, comportamento e ideologias. Ainda, percebeu-se que as palavras apresentadas são bastante distintas, sugerindo que os estudos sobre as relações raciais no Brasil devem ter uma área temática definida. Quanto as áreas temáticas, os estudos organizacionais que deveriam abrigar grande quantidade de pesquisas representaram apenas $28,5 \%$ das publicações. O marketing é o que detém maior acervo sobre o tema. Mas esses resultados estão comprometidos devido a pesquisas publicadas em diversos periódicos.

Sobre os resultados preferiu-se separá-los em relação à iniciativa pública e privada. Nas publicações referentes as organizações privadas percebeu-se a necessidade de resgatar 0 debate sobre as relações étnico raciais (LORENZO,2012), de identificar os papeis exercidos pelos negros e pardos na mídia de massa (ACEVEDO et al., 2008; FARIA et al., 2013; FARIA et al., 2014), de entender os comportamentos desses consumidores, bem como suas representatividades nas classes sociais (OLIVEIRA, 2007).

Nas organizações públicas a maioria das pesquisas tenta discutir o sistema de cotas aplicadas as universidades brasileiras, estas buscam verificar através da análise do discurso as opiniões (do público alvo) sobre o sistema de cotas (MAGGIE, 2006; SANTANA et al., 2006). Outras pesquisas tentam medir a efetividade das políticas públicas de acesso a universidade ao desempenho dos estudantes beneficiados pelas cotas e a dos não beneficiados, bem como a 
permanência destes estudantes quando comparados aos estudantes não cotistas (SARAIVA \& NUNES, 2011; BEZERRA \& GURGEL, 2012). E diferente do contexto acima apresentado destacam-se a pesquisa de IIZUKA (2006) que identificou possíveis fatores que deram origem ao sistema de cotas brasileiro e ROSA $(2006$; 2014) que propõe uma comparação das ações afirmativas para negros no Brasil com as já aplicadas nos Estados Unidos da América apontando pontos de conflito e sugerindo possíveis impactos culturais.

Nas referências bibliográficas, observou-se a existência da maioria de referências nacionais, as referencia internacionais constituem 37,4\%. Esse aspecto é considerado positivo uma vez que nacionaliza estudos muito característicos de fatores históricos e sociais. Quanto aos autores citados não se percebe a repetição dos mesmos autores, uma das poucas exceções refere-se a obra Casa grande e Senzala quanto retrata os relatos históricos. Quanto à qualidade das citações é possível analisar a presença de citações de Darcy Ribeiro, Cristovam Buarque, Maria Tereza Fleury e Miguel Caldas o que reflete determinado grau de requinte ao citar a elite de determinadas divisões bibliográficas brasileiras.

Outras observações relevantes são que as divisões dos eventos como o EnEO e EnANPAD destinadas a tratar da diversidade, preocuparam-se na maior parte das vezes em tratar das relações de gêneros e quase nunca das relações raciais. Tal tema ganha espaço nas publicações em divisões de administração pública por que existem as políticas que motivam o debate.

A título de curiosidade, somente a revista Educação e Sociedade publicou 11 artigos no período investigado sobre o tema. Nota-se que os números de publicações envolvendo as palavras - chave desta pesquisas são bem maiores em periódicos de educação, psicologia e antropologia.

Por fim, são considerados pontos relevantes dessa pesquisa a pequena quantidade de trabalhos publicados sobre 0 tema, bem como, as ideias controversas sobre o sistema de cotas que garante o acesso as universidades federais brasileiras. Ao iniciar esta pesquisa esperava-se identificar mais trabalhos sobre o assunto. Sugere-se pesquisas futuras para responder se os estudos organizacionais é preconceituoso em não abordar o tema profundamente e comparar essa contagem bibliográfica a de demais áreas e verificar a discrepância.

\section{CONCLUSÃO}

Diante da categorização realizada nos principais periódicos de administração sobre as etnias raciais observou-se que as ideias dos autores estudados se segmentavam em dois grupos: os autores que narram sobre a iniciativa privada, e os autores que narram sobre as instituições públicas. Foi evidente que o primeiro grupo busca sempre enriquecer os estudos nessa área e ainda sugere pesquisas futuras. No segundo grupo os debates foram considerados um pouco mais críticos e dividiam as ideias de autores a favor e contra as cotas.

Conclui-se que as pesquisas sobre etnias raciais nos estudos organizacionais brasileiros precisam ser aprofundados e que a área constituí-se campo fértil para novos estudos. Diante do levantamento realizado conscientiza-se sobre a necessidade de trabalhos inéditos sobre as relações raciais nas organizações brasileiras. Faltam trabalhos aplicados, principalmente, a área de gestão de pessoas, com o objetivo de identificar os percentuais de afrodescendentes atuando nas organizações brasileiras, bem como as diferenças salariais e as ações afirmativas adotadas. 


\section{REFERÊNCIAS}

ACEVEDO, C. R.; NOHARA, J.J.; Interpretações sobre os retratos dos afrodescendentes na mídia de massa. RAC, edição Especial 2008. Disponível em: <http://www.scielo.br/scielo.php?script=sci_arttext\&pid=S1415-65552008000500006\&ln $\mathrm{g}=\mathrm{en} \& \mathrm{nrm}=$ iso $>$ doi: http://dx.doi.org/10.1590/S1415-65552008000500006.

BRASIL. Lei 12.990, de 09 de junho de 2014. Diário Oficial da União, Brasília, DF, 10 de junho de $2014 . \quad$ Seção 1. Disponível em: $<$ http://pesquisa.in.gov.br/imprensa/jsp/visualiza/index.jsp?.jornal=1\&pagina=3\&data $=10$ / 06/2014>

BRASIL. Lei 12.711, de 29 de agosto de 2012. Diário Oficial da União, Brasília, DF, 30 de agosto de 2012. Seção 1. Disponível em: $<$ http://pesquisa.in.gov.br/imprensa/jsp/visualiza/index.jsp?.jornal=1\&pagina $=1$ \&data $=30 /$ 08/2012>

BEZERRA, T.; GURGEL, C. R. M.. As Políticas públicas de cotas na UFRJ: desempenho e inclusão. Anais do EnAPG, 2012. Disponível em: <http://www.anpad.org.br/diversos/trabalhos/EnAPG/enapg_2012/2012_EnAPG407.p df $>$

DILMA sanciona lei de cotas para o serviço público. Disponível em: $<$ http://www2.planalto.gov.br/centrais-de-conteudos/videos/dilma-sanciona-lei-de- cotaspara-o-servico-publico>

FARIA, S. G. S.; NOHARA, J. J.; LOPES, E. L.; ACEVEDO, C. R.; CAMPANARIO, P. M.. Uma analise das representações dos afrodescendentes nas propagandas de jornais paulistas. Pretexto v. 15 n. 1, 2014. p. 62-85. Disponível em:< http://www.fumec.br/revistas/pretexto/article/view/1947>

FARIA, S. G. S.; NOHARA, J. J.; LOPES, E. L. Uma analise dos Afrodescendentes nas Propagandas de Jornais Paulistas. Anais do EnANPAD, 2013. Disponível em: < http://www.anpad.org.br/admin/pdf/2013_EnANPAD_MKT1314.pdf>

IIZUKA, E. S.. A política de cotas nas universidades brasileiras: como ela chegou a agenda de políticas públicas. Anais do EnAPG, 2006. Disponível em: <http://www.anpad.org.br/diversos/trabalhos/EnAPG/enapg_2006/2006_ENAPG398.p>

LORENZO, R. A.. Ações afirmativas para afrodescendentes articuladas a partir de parcerias intersetoriais: uma análise argumentativa do caso geração XXI. O\&S n. 63, 2012. Disponível em: <http://www.scielo.br/scielo.php?script=s ci_arttext\&pid=S198492302012000400008\&lng=en\&nrm=iso > doi:92302012000400008.

MAGGIE, Y.. Racismo e anti-racismo: preconceitos, discriminação e os jovens estudantes nas escolas cariocas. Educação e Sociedade, v. 27, n. 96, 2006. Disponível em: http://www.scielo.br/pdf/es/v27n96/a06v2796.pdf doi: 73302006000300006

MELLO, M. F. F.; SILVA, F. C.; MOURA, L. S.. A adoção da política de cotas nas 
universidades públicas brasileiras e suas repercussão no ensino superior do país. Anais do EnAPG, 2006. Disponível em: < http://www.anpad.org.br/diversos/trabalhos/EnAPG/enapg_2006/2006_ENAPG61.pdf>

OLIVEIRA, J. S.. Gestão da diversidade: o desafio dos negros nas organizações brasileiras. Anais do EnANPAD, 2007. Disponível em: < http://www.anpad.org.br/admin/pdf/GPR-A1917.pdf>

ROSA, A. R.. Relações raciais e estudos organizacionais no Brasil. RAC, v. 18, n. 3, 2014. Disponível em: <http://www.scielo.br/scielo.php?script=sci arttext\&pid=S1415-65552014000300002\&Ing=en\&nrm=iso> doi: 19827849rac20141085.

ROSA, A. R.. Relações raciais e estudos organizacionais no Brasil: Dimensões Esquecidas de Um Debate Que (Ainda) Não Foi Feito. Anais do EnANPAD, 2012. Disponível em: <http://www.scielo.br/pdf/rac/v18n3/v18n3a02.pdf>

SANTANA, S. G.; NOHARA, J. J.; LOPES, E. L.. Um estudo longitudinal na representação dos afrodescendentes na mídia impressa brasileira. Anais do EMA, 2012. Disponível em:<http://www.anpad.org.br/adm/pdf/2012_EMA256.pdf>

SARAIVA, L. A. S.. NUNES, A.S.. A efetividade de programas sociais de acesso à educação superior: o caso PROUNI. RAP v. 45, $2011 . \quad$ Disponível em: $<$ http://www.scielo.br/scielo.php?script=sci_arttext\&pid=S0034-

$76122011000400003 \&$ Ing=en\&nrm=iso $>$. doi: 1590/S0034-76122011000400003. 